\title{
03 A COMPREHENSIVE APPROACH FOR REDUCING THE INCIDENCE OF DOMESTIC BURNS IN RURAL UPPER EGYPT
}

doi:10.1136/injuryprev-2012-040590c.3

Project Burn Prevention, an educational programme about burn prevention and safety, was implemented in Rural Upper from January 2008 through November 2009. The programme consisted of two components: a school-initiated intervention (puppet theatre for primary school children and awareness seminars for secondary school students), and a community-initiated intervention (home visits for housewives, women home based seminars and community awareness seminars). Estimates of burn incidence and the prevalent practices for the first aid measures within the community were made on the whole community for a 1-year period before the programme, and the 12 months after the programme. Analysis of burn incidence during and after the interventions showed that the programme intervention have brought a significant improvement in the knowledge, attitude and practices of the community members (house head and house wife) about cooling the burn, gas leakage testing. The community members did not have any good impression and trust about the usefulness of calling the fire-fighters to help in prevention activities (in case of gas leakage detection). Reduction in the rate of burn injuries as well as a significant improvement of the first aid measures for burns inside the house. 